\title{
Gümüş Katkılı Bakır (II) Oksit İnce Filmlerin Yüzey Aktif Madde Yardımıyla SILAR Metoduyla Büyütülmesi
}

\author{
Halit Çavuşoğlu ${ }^{1 *}$ \\ ${ }^{1}$ Selçuk Üniversitesi, Fen Fakültesi, Fizik Bölümü, Konya, Türkiye (ORCID: 0000-0002-7215-651X)
}

(İlk Geliş Tarihi 20 Şubat 2019 ve Kabul Tarihi 13 Mart 2019)

(DOI: 10.31590/ejosat.529778)

\begin{abstract}
ATIF/REFERENCE: Çavuşoğlu, H. (2019). Gümüş Katkılı Bakır (II) Oksit İnce Filmlerin Yüzey Aktif Madde Yardımıyla SILAR Metoduyla Büyütülmesi. Avrupa Bilim ve Teknoloji Dergisi, (15), 412-419.

$\ddot{\mathbf{O} z}$

Bu çalışmada, gümüş ( $\mathrm{Ag})$ katkılı bakır(II) oksit $(\mathrm{CuO})$ ince filmler, cam yüzeyler üzerinde, oda sıcaklığında bir yüzey aktif maddesi yardımıyla ardışık iyonik tabaka adsorpsiyon ve reaksiyon (SILAR) tekniği ile büyütülmüsşür. Farklı konsantrasyonlardaki Ag'nin (0 $\%$ ila $3.0 \mathrm{M} \%$ ) sodyum sitrat yüzey aktif maddesi içeren $\mathrm{CuO}$ ince filmlerin yapısal, morfolojik ve optiksel özellikleri üzerindeki etkileri incelenmiştir. Üretilen tüm ince filmlerin yapısal analizi, X-ışını difraktometresi (XRD) ile gerçekleştirilmiştir. Yapısal analiz sonuçlarına göre, tüm filmlerin çok kristalli bir yapıda ve monoklinik kristal formda olduklarını doğrulamaktadır. Farklı oranlarda katkılanan Ag konsantrasyonlarına bağlı olarak, kristalit büyüklüğü değerleri 14.83 ila $17.09 \mathrm{~nm}$ arasında değişmiştir. $\mathrm{CuO}$ ince filmlerin yüzey morfolojisi metalürjik mikroskop kullanılarak incelenmiştir. Yüzey çalışmaları $\mathrm{CuO}$ nanoyapılarının film yüzeylerinde homojen olarak dağıldığını göstermiştir. Tüm ince filmlerin optik analizleri UV-Vis-NIR spektrofotometresi kullanılarak incelenmiştir. Optiksel analiz sonuçları, $\mathrm{CuO}$ ince filmlerin optik bant aralığı enerjilerinin, gümüş konsantrasyonunun $0 \mathrm{M} \%$ 'den 2.0 M\%'ye yükselmesiyle, $1.34 \mathrm{eV}$ 'den $1.72 \mathrm{eV}$ 'ye yükseldiğini ortaya koymuştur. Gümüş konsantrasyonunun $3.0 \mathrm{M} \%$ 'ye yükseltilmesiyle, bant aralığı enerjisi $1.68 \mathrm{eV}$ 'ye düşmüştür. Tüm filmlerin ortalama geçirgenliği, artan gümüşs konsantrasyonu ile 2.0 \%'dan 32.5 \%'e yükselmiştir.
\end{abstract}

Anahtar Kelimeler: $\mathrm{CuO}$ ince film, Katkılama, Yüzey aktif madde, Gümüş, SILAR.

\section{Surfactant-Assisted Growth of Silver-Doped Cupric Oxide Thin Films Fabricated by SILAR Method}

\begin{abstract}
In the present work, silver-doped cupric oxide $(\mathrm{CuO})$ thin films have been deposited on glass substrates by a surfactant-assisted successive ionic layer adsorption and reaction (SILAR) technique at room temperature. The effects of different concentrations of silver from 0 to $3.0 \mathrm{M} \%$ on the structural, morphological, and optical properties of $\mathrm{CuO}$ thin films with sodium citrate surfactant were studied. The structural analysis of all produced thin films was performed with X-ray diffractometer (XRD). Structural analysis confirm that all the films were polycrystalline nature having a monoclinic crystalline form. The crystallite size values ranged from 14.83 to $17.09 \mathrm{~nm}$ depending on the concentration of silver doping in different proportions The surface morphology of CuO thin films was examined using metallurgical microscope studies. Surface studies showed that homogeneously distributed CuO nanostructures on the film surfaces. Optical analysis of all thin films were examined using UV-Vis-NIR spectrophotometer. The optical analysis results revealed that optical band gap energies of the $\mathrm{CuO}$ thin films increased from 1.34 to $1.72 \mathrm{eV}$ with increasing molarity of silver concentration from $0 \mathrm{M}$ to $2.0 \mathrm{M} \%$. For further increase of molarity to $3.0 \mathrm{M} \%$, the band gap energy decreased to $1.68 \mathrm{eV}$. The average transmittance of all the films had increased from $2.0 \%$ to $32.5 \%$ with the increasing silver concentration.
\end{abstract}

\footnotetext{
*Sorumlu Yazar: Selçuk Üniversitesi, Fen Fakültesi, Fizik Bölümü, Konya, Türkiye, ORCID: 0000-0002-7215-651X, hcavusoglu@ @elcuk.edu.tr
} 
Keywords: $\mathrm{CuO}$ thin film, doping, surfactant, silver, SILAR.

\section{Giriş}

Hem bilimsel hem de teknolojik açıdan ele alığında, metal oksitler çok önemli bir malzeme sınıfını teşkil etmektedirler. Son zamanlarda bu alanda yapılan araştırmalar, özellikle metal oksit ince filmler üzerinde yoğunlaşmıştır. Öne çıkan metal oksit malzemeler arasında çinko oksit (ZnO) (Znaidi, 2010), kadmiyum oksit (CdO) (Chandiramouli ve Chandiramouli, 2013), kalay oksit $\left(\mathrm{SnO}_{2}\right)$ (Das ve Jayaraman, 2014), nikel oksit (NiO) (Ukoba ve ark., 2018), mangan oksit (Xia ve ark., 2011) ve kuprik oksit $(\mathrm{CuO})$ (Dey, 2018) sayılabilir. Bu metal oksitler arasında CuO ince filmler, optik, yarı iletken, manyetik, ve optoelektronik özellikler başta olmak üzere çok işlevli özelliklerin ilginç bir kombinasyonunu göstermektedirler (Vila ve ark., 2010; Raghavendra ve ark., 2018; Shrividhya ve ark., 2014; Baturay ve ark., 2016). CuO ince filmler, gaz sensörleri, güneş pilleri, katalizörler ve lityum pilleri gibi elektronik cihazlarda birçok uygulamaları bulunmaktadır (Papurello ve ark., 2017; Baratto ve ark., 2015; Jackson ve ark., 2016; Diachenko ve ark., 2018; Ramírez-Ortiz ve ark., 2001). CuO malzemelerin tercih sebebi k1lınmasında en önemli unsurlar arasında; maliyet etkinliği, mükemmel reaktivitesi ve toksik olmaması sayılabilir (Gevorkyan ve ark., 2012). CuO, optik bant aralık değeri 1.2 $\mathrm{eV}$ ile $1.8 \mathrm{eV}$ arasında değişen monoklinik yapıya sahip bir yarı iletken malzemedir (Dodoo-Arhin ve ark., 2012).

Günümüzde, $\mathrm{CuO}$ ince filmlerin hazırlanması için çeşitli fiziksel ve kimyasal biriktirme teknikleri kullanılmaktadır. Yapılan gözlemler sonucunda, kimyasal biriktirme tekniklerinin, fiziksel tekniklere nazaran daha ekonomik ve uygulanabilir olduğu sonucuna varılmıştır. Başlıca kimyasal biriktirme teknikleri arasında sol-gel spin kaplama metodu [Al-Ghamdi ve ark., 2009; Qin ve ark., 2010; Bae ve Choi, 1999), ultrasonik sprey piroliz tekniği [Oh ve ark., 2007; Sing ve ark.; 2011), mikrodalga ve hidrotermal sentezi [Qiu ve ark., 2012; Yang ve ark., 2011), elektrokimyasal biriktirme (Mukherjee ark., 2011), kimyasal banyo biriktirme (CBD) [Terasako ve ark., 2015; Nair ve ark., 1999) ve ardışı iyonik tabaka adsorpsiyon ve reaksiyon (SILAR) [Cavusoglu ve Aydin, 2019; Rafea ve Roushdy, 2009; Das ve Mitra, 2018) yöntemi sayılabilir. Bu kimyasal biriktirme teknikleri arasında, SILAR yöntemi, kontrollü film kalınlığının elde edilmesi, düşük biriktirme sıcaklığına sahip olması ve vakum ortamına gerek duyulmaması gibi özelliklerinden ötürü ince filmlerin hazırlanması için uygun bir tekniktir.

Solüsyon bazlı depolama tekniklerinde, nanoyapılı ince filmlerin fiziksel özelliklerini geliştirmek amacıyla büyütme sırasında çözelti içerisine çeşitli yüzey aktif maddeleri (sürfaktan) ve katkı maddeleri (dopant) ilave edilir. Literatürde, yüzey aktif maddeler ve metal malzemelerin, polikristal ince filmlerin büyüme, film kalınlığı, yapısal, morfolojik, optik ve elektriksel özelliklerine etkileri ile ilgili çeşitli çalışmalar bulunmaktadır. Das ve Alford (Das ve Alford, 2013) düşük sıcaklıkta mikrodalga tavlama tekniği ile üretilen bakır(II) oksit filmlere gümüş katkılayarak, elde edilen malzemenin mikroyapısal ve optiksel parametrelerindeki değişimleri gözlemlemişlerdir. Huang ve ark. (Huang ve ark., 2012) $\mathrm{CuO}$ nanolevhalara gümüş katkılayarak süperkapasitör uygulamalarda kullanım açısından elektrokimyasal davranışlarına önemli katkılar sağladıklarını tespit etmişlerdir. Fadavieslam (Fadavieslam, 2018) ise sprey piroliz tekniği ile hazırlamış olduğu kalay sülfür ince filmlerin optoelektronik uygulamalarda kullanımı açısından gümüş katkılamanın fiziksel özelliklerine olumlu yönde etkilerinin olduğunu tespit etmiş̧tir. Agawane ve ark. (Agawane ve ark., 2012) ise kimyasal banyo tekniği kullanılarak büyütülen çinko sülfür $(\mathrm{ZnS})$ ince filmlerin büyütülme mekanizmasına tri-sodyum sitrat yüzey aktif maddesinin etkilerini kapsamlı bir şekilde incelemişlerdir. Ramírez-Ceja ve ark. (Ramírez-Ceja ve ark., 2016) da aynı tekniği kullanarak PbS ince filmlerin büyütülmesine sodyum sitratın etkilerini detaylı olarak irdelemişlerdir. Kihal ve ark. (Kihal ve ark., 2017) ise elektrokaplama yöntemiyle elde ettikleri SnS ince filmlerin güneş pili uygulamalarına sodyum sitratın etkilerini analiz etmişlerdir.

Literatürde yapılmış olan çalışmalar göstermektedir ki, çözelti bazlı sentezlenmiş olan ince filmlerin yapısal, morfolojik ve optik özelliklerin geliştirilmesinde Ag ve sodyum sitrat sıklıkla kullanılmaktadır. Bu bağlamda, mevcut çalışmada SILAR tekniğiyle CuO ince filmlere sodyum sitrat yüzey aktif maddesinin yüzdelik oranı sabit tutularak (1.0 M\%), farklı konsantrasyonlara sahip Ag (sırasıyla $1.0 \mathrm{M} \%$, $2.0 \mathrm{M} \%$ ve $3.0 \mathrm{M} \%$ ) katkılanmıştır. Sentezlenmiş olan $\mathrm{CuO}$ ince filmlerin yapısal, morfolojik ve optik özellikleri üzerine Ag konsantrasyon oranlarının etkisi araştırılmıştır.

\section{Materyal ve Metot}

\subsection{CuO İnce Filmlerin Büyütülmesi}

Katkısı $\mathrm{CuO}$ ve $1.0 \mathrm{M} \%$ konsantrasyona sahip sodyum sitratlı farklı konsantrasyonlardaki nanoyapılı $\mathrm{Ag}$ katkılı $\mathrm{CuO}$ ince filmler, oda sıcaklığında kalsiyum oksit karışımı cam altlıklar üzerinde büyütüldü. Filmlerin büyütülme işlemine geçilmeden önce cam altlıklar sırasıyla aseton, izopropil alkol ve deiyonize su kullanılarak ultrasonik banyoda 10 dakika süreyle organik kirlerden arındırıldı. Temizlenen cam altlıklar etüvde $100{ }^{\circ} \mathrm{C}$ 'de kurutulmuştur. Daha sonra, $\mathrm{CuO}$ filmlerin elde edilmesi için bakır kaynağı olarak bakır(II) klorür dihidrat $\left[\mathrm{CuCl}_{2} \cdot 2 \mathrm{H}_{2} \mathrm{O}\right]$ kimyasal tuzu kullanılmıştır. Çözelti molaritesi $0.1 \mathrm{M}$, miktarı ise $100 \mathrm{~mL}$ olarak hazırlanmıştır. Hazırlanan $\mathrm{CuCl}_{2}$ çözeltisinin $\mathrm{pH}$ değeri yaklaşık 11 olana kadar, $25 \%$ derişimli sulu amonyum hidroksit çözeltisi eklendi. Oksitleyici olarak $90{ }^{\circ} \mathrm{C}$ sıcaklıktaki $100 \mathrm{~mL}$ 'lik saf su kullanılmışır. Çözeltilerin hazırlanmasının ardından daha önceden temizlenmiş̧ olan cam altlıklar üzerinde film büyütme işlemine geçilmiştir. Filmlerin büyütülmesi süreci oda sıcaklığında iki aşamalı olarak gerçekleştirilmiş̧ir. İlk adımda cam altlıklar $90{ }^{\circ} \mathrm{C}$ sıcaklıktaki bakır klorür-amonyum hidroksit bileşik çözeltisine $\left(\left[\mathrm{Cu}\left(\mathrm{NH}_{3}\right)_{4}\right]^{2+}\right)$ daldırılıp $20 \mathrm{~s}$ bekletilmesi sonucunda, bakır iyonlarının cam yüzeyine tutunması sağlanır. İkinci adımda ise $90{ }^{\circ} \mathrm{C}$ sicaklıktaki saf suya daldırlıp 20 s bekletilmesiyle $\mathrm{OH}^{-}$iyonlarının daha önce $\mathrm{Cu}^{2+}$ iyonlarıla reaksiyona girerek $\mathrm{Cu}(\mathrm{OH})_{2}$ tabakasının oluşumu gerçekleşir. Bu döngü $10 \mathrm{kez}$ tekrarlanmıştır. Daldırma işlemleri tamamlandıktan sonra filmler kurumaya bırakılmış ve daha sonra hava ortamındaki $\mathrm{OH}^{-}$dan kurtulmak amacıyla $400{ }^{\circ} \mathrm{C}$ sıcaklıkta 1 saat süreyle kül firınında tavlanmıştır. Katkısız $\mathrm{CuO}$ ince filmler elde edilmesinden sonra molaritesi $0.1 \mathrm{M} \mathrm{CuCl}_{2}$ çözeltisine $1.0 \mathrm{M} \%$ sodyum sitrat $\left(\mathrm{Na}_{3} \mathrm{C}_{6} \mathrm{H}_{5} \mathrm{O}_{7}\right)$ ve 1.0 $\mathrm{M} \%$, $2.0 \mathrm{M} \%$ ve $3.0 \mathrm{M} \%$ konsantrasyonlarına sahip gümüş nitrat $\left(\mathrm{AgNO}_{3}\right)$ ilave edilmiştir. Hazırlanan bu çözeltiler yardımıyla 
katkısız olarak elde edilen $\mathrm{CuO}$ ince filmlerin deney şartlarını kullanarak katkılı $\mathrm{CuO}$ ince filmler elde edilmiştir. Elde edilen katkılı ince filmler kül firınında aynı şartlarda tavlanmıştır.

\subsection{CuO İnce Filmlerin Karakterizasyonu}

Üretilen tüm ince filmlerin yapısal analizi, Bruker D8 Advance X-ışını difraktometresi (Cu-Ka, $\lambda=1.5418 \AA$, XRD, Bruker AXS Inc., Madison, WI, ABD) ile gerçekleştirilmiştir. Kırınım açılarının aralığ $30^{\circ}$ ile $70^{\circ}$ arasında seçildi. Büyütülen filmlerin yüzey morfolojileri, Zeiss Axioscope metalürjik mikroskop (MM, Carl Zeiss, Oberkochen, Almanya) kullanılarak karakterize edilmiştir. Tüm ince filmlerin soğurma ve geçirgenlik spektrumları 190-1100 nm aralığında UV-Vis-NIR spektrofotometresi (Jasco Inc., MD, ABD) kullanılarak kaydedildi.

\section{Araştırma Sonuçları ve Tartışma}

\subsection{Yapısal Analiz}

Katkısız CuO ve $1.0 \mathrm{M} \%$ sodyum sitrat içeren $1.0 \mathrm{M} \%, 2.0 \mathrm{M} \%$ ve $3.0 \mathrm{M} \%$ Ag katkılı CuO ince filmlerin yapısal özellikleri Xışını kırınımı (XRD) analizi ile incelenmiştir. XRD parametresi kullanılarak pik şiddetleri, kristalit boyutu ve zorlanma derecesi gibi parametreler hesaplandı. Şekil 1'de tüm ince filmlere ait XRD kırınım desenleri gösterilmiştir. Üretilen CuO ince filmlerin tümü tamamen kristal bir yapıda olup tüm kırınım desenleri monoklinik CuO fazına karşılık gelmektedir (JCPDS dosya no. 01-080-0076). Şekil l'deki XRD desenlerinden $\mathrm{CuO}$ ince filmlerine ait (111) ve (111) düzlemlerinin diğer düzlemlere kıyasla en baskın iki düzlem olduğu görülmektedir. Bu iki baskın düzlemin dışında, yedi tane daha kırılma düzlemi bulunmaktadır. Bunlar sırasıyla (110), (202), (020), (202), (113), (311) ve (220) düzlemleridir. CuO'nun diğer fazlarına karşılık gelen başka hiçbir faz tespit edilememiştir. CuO ince filmlerin baskın olan (111) ve (111) düzlemlerine ait pik şiddeti değerleri Şekil 1'de gösterilip, Tablo 1'de listelenmiştir. Bu değişim analiz edildiğinde $\mathrm{CuO}$ ince filmlerin düzlemlerindeki pik şiddetleri, Ag katkılama oranı arttıkça azaldığı gözlenmiştir.

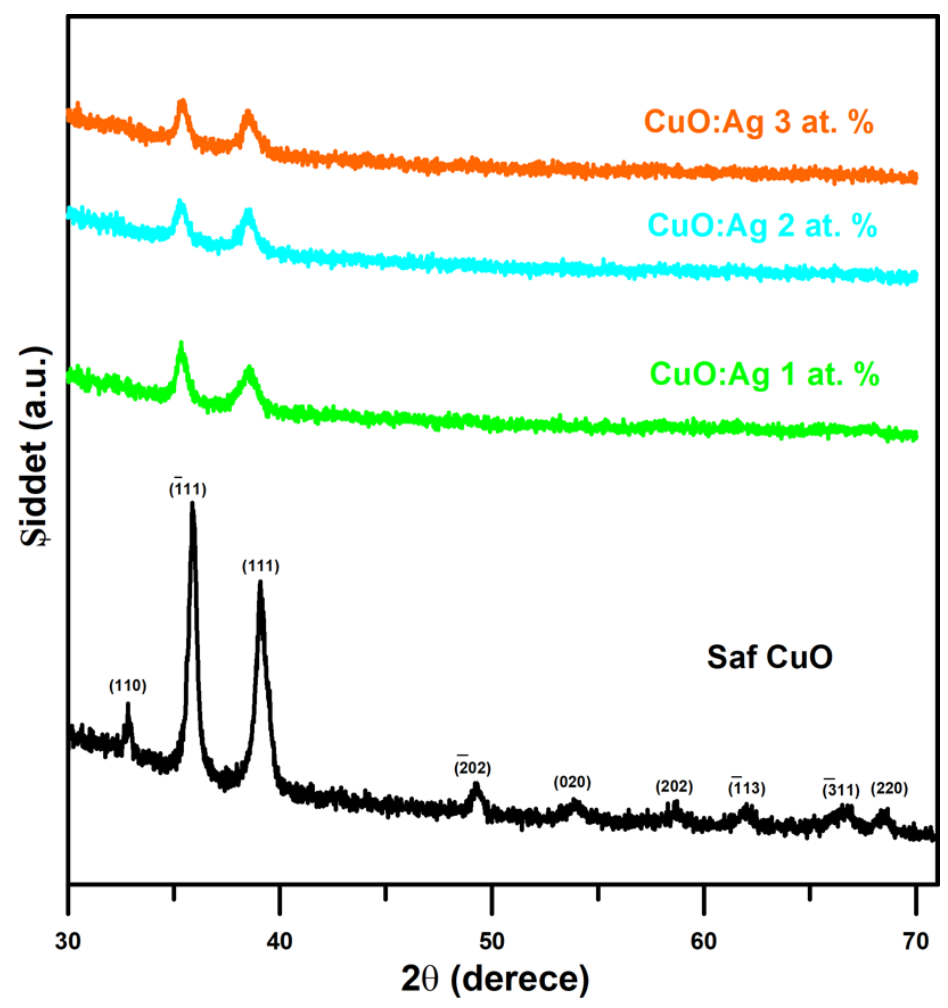

Şekil.1. Katkısız $\mathrm{CuO}$ ve $1.0 \mathrm{M} \%, 2.0 \mathrm{M} \%$ ve $3.0 \mathrm{M} \% \mathrm{Ag}$ katkılı $\mathrm{CuO}$ ince filmlerin XRD desenleri. 
Farklı konsantrasyonlarda Ag katkısının $\mathrm{CuO}$ ince filmlerin mikroyapısal parametrelerinden kristalit boyut (D) ve zorlanma derecesi $(\varepsilon)$ üzerindeki etkileri de incelenmiştir. $\mathrm{CuO}$ ince filmlere ait kristalit boyutu (D) ve zorlanma derecesi $(\varepsilon)$ değerleri, aşağıldaki denklemler kullanarak elde edilmiştir (Çavuşoğlu, 2019);

$D=\frac{0.94 \lambda}{\beta \cos \theta}$

ve

$\varepsilon=\frac{\beta \cos \theta}{4}$

Burada $\theta$ Bragg kırılma açısı, $\beta$ pik yarı yükseklik genişliği (FWHM) değeri ve $\lambda$ ise $\mathrm{X}$ ışını dalga boyudur. Tüm $\mathrm{CuO}$ ince filmlere ait ortalama kristalit boyutu ve zorlanma derecesi değerleri Tablo-1'de gösterilmiştir. Tablo 1'de görüldüğü gibi, CuO ince filmlerine ait kristalit büyüklüğü değerleri, Ag katkılama oranına bağlı olarak değişkenlik göstermiştir.

Tablo 1. Katkısı CuO ve farklı konsantrasyonlarda $\mathrm{Ag}$ katkılı CuO ince filmlerin pik şiddetleri, kristalit boyutu, zorlanma dereceleri ve bant aralık değgerleri.

\begin{tabular}{cccccc}
\hline Numune & \multicolumn{2}{l}{$\begin{array}{l}\text { Pik Şiddetleri }(\mathbf{c p s}) \\
(\overline{\mathbf{1} 11})\end{array}$} & $\begin{array}{c}\text { Kristalit } \\
\text { Boyutu } \\
(\mathbf{n m})\end{array}$ & $\begin{array}{c}\text { Zorlanma } \\
\text { Derecesi } \\
(\varepsilon) \times 1^{-3}\end{array}$ & $\begin{array}{c}\text { Bant } \\
\text { Aralığ } \\
(\mathbf{e V})\end{array}$ \\
\hline $\mathbf{C u O}$ & 1645 & 1180 & 16.16 & 2.32 & 1.34 \\
$\mathbf{A g}_{\mathbf{0 . 0 1}} \mathbf{C u} 0.99$ & 685 & 571 & 14.83 & 2.52 & 1.52 \\
$\mathbf{A g}_{\mathbf{0 . 0 2}} \mathbf{C u}_{\mathbf{0 . 9 8}} \mathbf{O}$ & 608 & 568 & 17.09 & 2.14 & 1.72 \\
$\mathbf{A g}_{\mathbf{0 . 0 3}} \mathbf{C u}_{\mathbf{0 . 9 7}} \mathbf{O}$ & 618 & 563 & 15.64 & 2.31 & 1.68 \\
\hline
\end{tabular}

Şekil 2'de, Ag konsantrasyonu ile kristalit boyutunun ve zorlanma derecesinin değişimini gösterilmektedir. Şekil 2 ve Tablo 1 'de görüldügü gibi, artan Ag konsantrasyonu sonucunda kristalit büyüklüğü değerleri ile zorlanma derecesi değerleri birbirleriyle zit bir şekilde değişim göstermektedir. Bir başka deyişle, Ag konsantrasyonu arttıkça kristalit büyüklügü artarken zorlanma derecesi değerleri azalmaktadır ya da azalma durumunda artış görülmektedir.

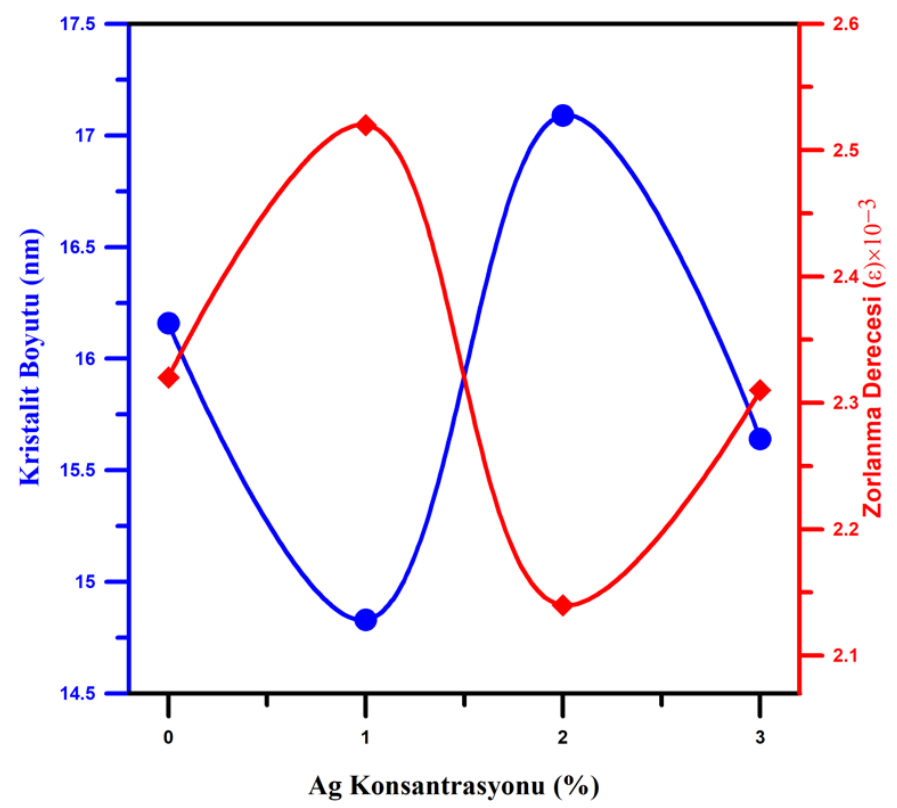

Şekil.2. Ag konsantrasyonlarının bir fonksiyonu olarak $\mathrm{CuO}$ ince filmlerin kristalit boyutunun zorlanma derecesine göre değişimi. 


\subsection{Yüzey Morfoloji Analizi}

\subsubsection{Metalürjik Mikroskop (MM) Analizi}

Yüzey morfolojisi, ince filmlerin fiziksel performanslarını etkileyen önemli faktörlerden biridir. Bu bağlamda metalürjik mikroskop (MM), Ag'nin $\mathrm{CuO}$ ince filmlerin yüzey morfolojileri üzerindeki etkilerini incelemek için kullanılmıştır. Katkısız CuO ve sırasıyla $1.0 \mathrm{M} \%, 2.0 \mathrm{M} \%$ ve $3.0 \mathrm{M} \%$ oranlarında Ag katkılı, $1.0 \mathrm{M} \%$ sodyum sitrat içeren CuO ince filmlerin MM görüntüleri Şekil 3(a-d)'de gösterilmiştir. Katkısız CuO ince filme ait mikroskop görüntüsü Şekil 3(a)'da görüldüğü üzere karanlık ve çukur bölgelerin bir hayli fazla olmadığı tespit edilmiştir. Bu durum bize üretilen ince filmin homojenliğinin yüksek olduğu göstermektedir. Şekil 3(b,c) incelendiğinde, $1.0 \mathrm{M} \%$ sodyum sitrat içeren $\mathrm{CuO}$ ince filme $1.0 \mathrm{M} \%$ ve $2.0 \mathrm{M} \%$ oranında Ag katkılandığında ilk etapta filmin homojenliği bozulmaya başladığı ve yüzey pürüzlülüğünün arttı̆̆1 gözlenmiştir. Şekil 3(d)'de ise Ag’nin katkılanma oranı 3.0 M\% olduğunda ise gayet parlak, homojen ve tekdüze bir yapı ile karşılaşılmaktadır. Buradan en yüksek oran olan 3.0 M\% Ag katkılaması ile pürüzlülüğün azaldığı ve parlaklığın belirgin şekilde arttığı görülmüştür. Böylece nanoyapılı CuO ince filmlerin yüzey morfolojisi üzerine Ag katkısının ciddi bir etkiye sahip olduğu tespit edilmiştir.

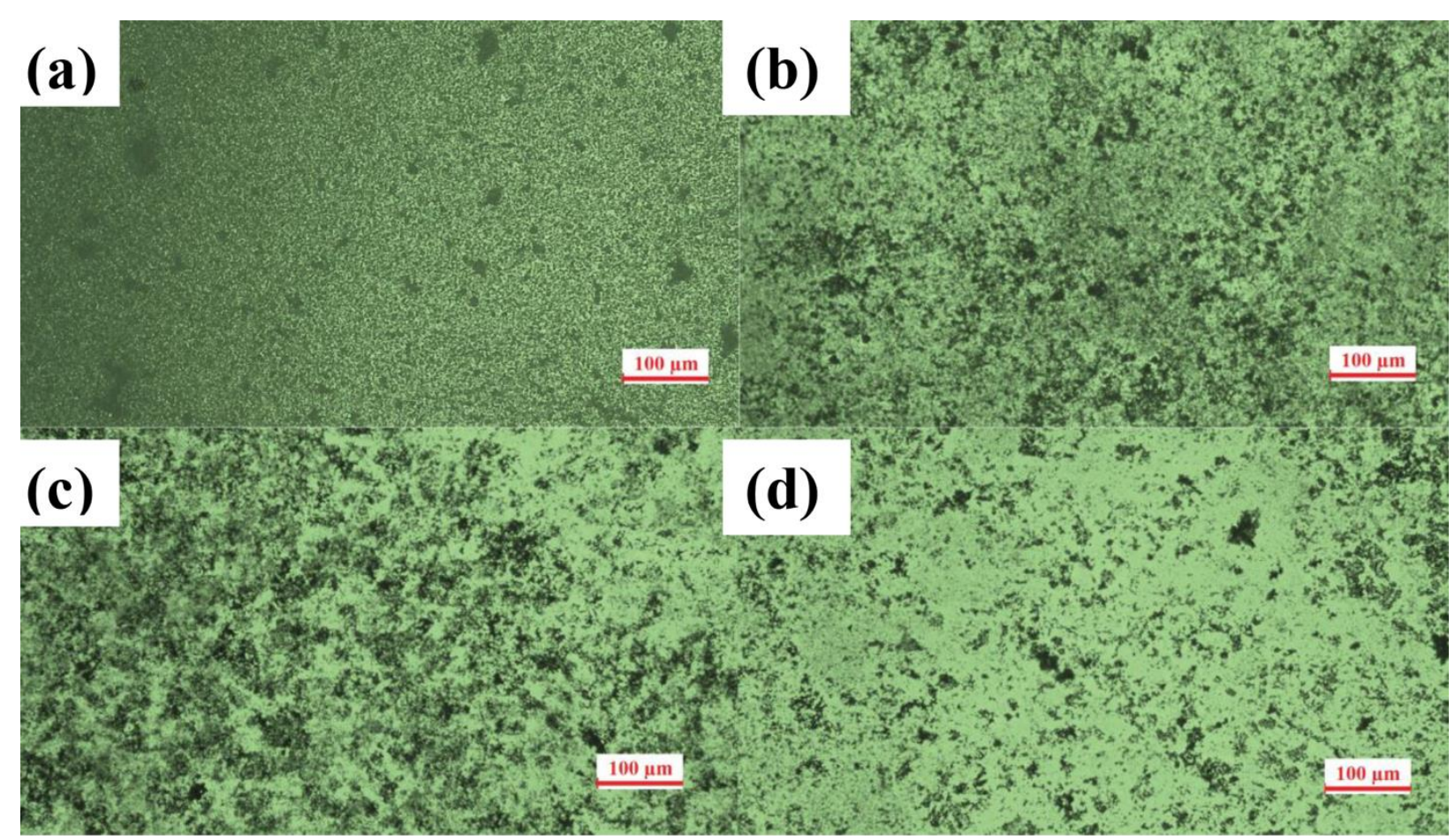

Şekil.3. (a) Katkısız CuO, (b) $1.0 \mathrm{M} \%$, (c) $2.0 \mathrm{M} \%$ ve (d) $3.0 \mathrm{M} \%$ Ag katkı1ı CuO ince filmlerin MM görüntüleri.

\subsection{Optiksel Analiz}

Katkısız ve farklı oranlarda Ag katkılı CuO ince filmlerin optik özellikleri UV-Vis spektrofotometre kullanılarak incelendi. Elde edilen ince filmlere ait bant aralığı değerleri, aşağıda yer alan bağıntı ile elde edilmiştir (Çavuşoğlu, 2018);

$\alpha h v=C\left(h v-E_{g}\right)^{m}$

Burada $m$ üstel bir sabit olup izinli doğrudan geçişlerde $1 / 2$ değerini alır. $E_{g}$ bant aralığı enerjisi, $v$ frekans, $h$ Planck sabiti, $C$ orantı sabiti ve $\alpha$ is soğurma katsayısıdır. Şekil 4'de katkısız CuO ve farklı konsantrasyonlarda Ag katkılanmış CuO filmlerin ( $\alpha$ hv) ${ }^{2}$ 'nin foton enerjisi olan hv'ye bağlı değişimleri görülmektedir. Elde edilen katkısız ve farklı konsantrasyonlarda Ag katkılı (1.0 M\%, 2.0 $\mathrm{M} \%, 3.0 \mathrm{M} \%) \mathrm{CuO}$ ince filmlerinin hesaplanan $\mathrm{E}_{\mathrm{g}}$ değerleri yaklaşık olarak sırasıyla $1.34,1.52,1.72 \mathrm{ve} 1.68 \mathrm{eV}$ olarak bulunmuştur ve Tablo 1'de listelenmiştir. Filmlerin optik bant aralık değerlerindeki bu değişiklik farklı oranlarda Ag katkılanması sonucunda sodyum sitrat içeren $\mathrm{CuO}$ filmlerin kristal yapılarındaki değişimin bir sonucudur. Yapısal analiz kısmında da belirtilen filmlerin kristalit boyutlarındaki değişism doğrudan malzemenin optik özellikleri etkilemektedir. 


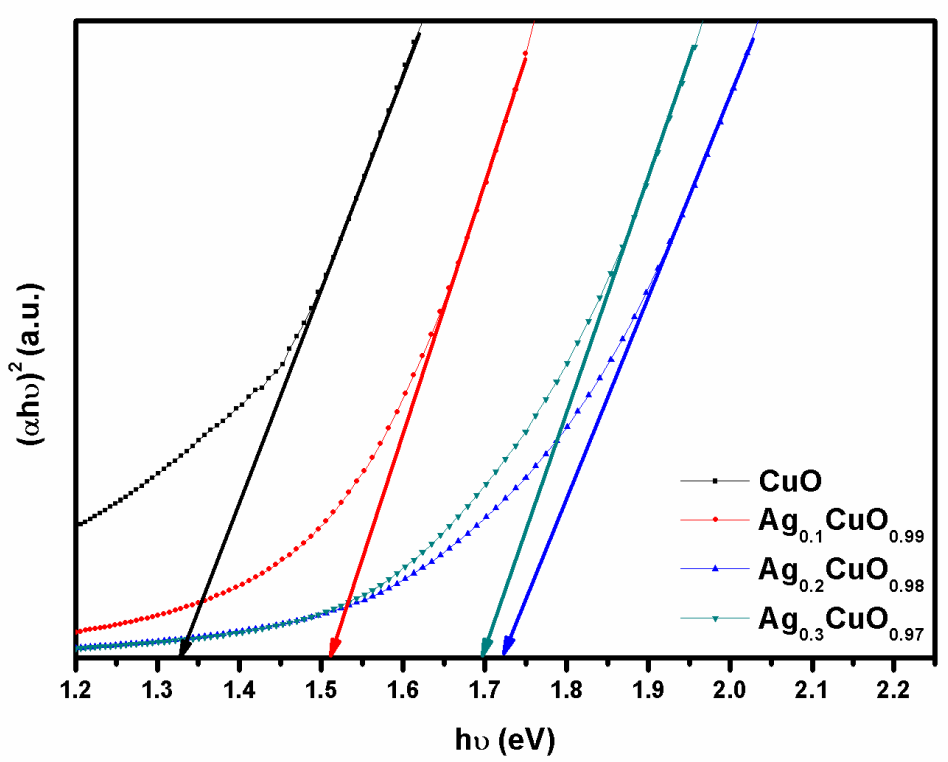

Şekil.4. Katkısız $\mathrm{CuO}$ ve farklı konsantrasyonlarda $\mathrm{Ag}$ katkılı $\mathrm{CuO}$ filmlerin $(\alpha h v)^{2}$ nin foton enerjisi (hv) ye göre değişimi.

$\mathrm{CuO}$ ince filmlerin optik geçirgenlik spektrumları, Şekil 5'te gösterildiği gibi 300-1100 nm spektral bölgesinde farklı Ag konsantrasyonlarında $1.0 \mathrm{M} \%, 2.0 \mathrm{M} \%, 3.0 \mathrm{M} \%$ ) elde edilmiştir. Şekil 5'te görüldüğü gibi, Ag katkısı olmadan elde edilen $\mathrm{CuO}$ ince filmlerin, en düşük geçirgenliğe ( 2.0 \%) sahiptir. Optik geçirgenlik, sulu büyüme çözeltisinde artan gümüş içeriği ile birlikte hızlı bir şekilde $\sim 2.0 \%$ 'dan $32.5 \%$ 'e yükselmiştir. Maksimum geçirgenlik ( $\% 32.5)$, 3.0 M\% gümüş içeriği ile gözlenmiştir. CuO ince filmlerin geçirgenlik değerindeki bu değişiklik, filmlerin kalınlık ve saydamlıklarındaki farklılıktan kaynaklandığı söylenebilir (Aly ve Akl, 2015; Sanguanruang ve ark., 2011).

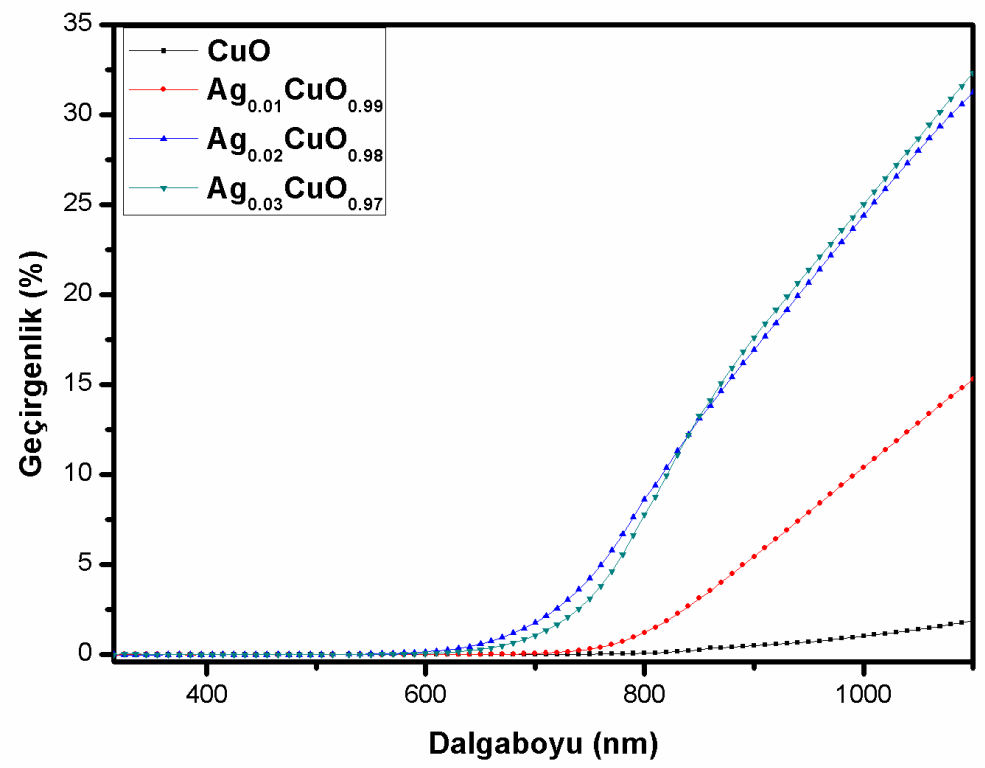

Şekil.4. Katkısız $\mathrm{CuO}$ ve farklı konsantrasyonlarda $\mathrm{Ag}$ katkılı $\mathrm{CuO}$ filmlerin optik geçirgenlik spektrumları. 


\section{Sonuç}

$\mathrm{CuO}$ ince filmler maliyeti uygun SILAR tekniği ile üretildi ve yapısal, morfolojik ve optik karakteristiklerine değişen gümüş konsantrasyonunun $(0.00 \mathrm{M} \%, 1.00 \mathrm{M} \%, 2.00 \mathrm{M} \%$ ve $3.00 \mathrm{M} \%)$ etkileri kapsamlı olarak incelendi. Kristalografik ve yüzey morfolojik özellikleri, gümüş katkılama derişimleri modüle edilerek modifiye edildi. $\mathrm{CuO}$ ince filmlerin kristalit boyutunun artan gümüş konsantrasyonu ile birlikte azaldığı gözlenmiş̧ir. Metalürjik mikroskop çalışmaları, $\mathrm{CuO}$ ince filmlerin yüzey morfolojisinin, büyütme çözeltisine gümüş ve sodyum sitrat ilavesiyle modifiye edildiğini ortaya koymuştur. Değişen gümüş konsantrasyonuna bağlı olarak ince filmlerin optik bant aralığı enerji değerleri oldukça değişmiştir. Filmlerin bant aralığı değerleri, gümüş konsantrasyonunun bir fonksiyonu olarak $1.34 \mathrm{eV}$ ile $1.72 \mathrm{eV}$ arasında değişmiştir. Sonuç olarak, bu çalışma sonucunda elde edilen SILAR yöntemiyle üretilen farklı gümüş konsantrasyonuna sahip $\mathrm{CuO}$ ince filmlerin, çeşitli optoelektronik cihaz uygulamaları için uygun olduğu öngörülmüştür.

\section{Teşekkür}

Bu çalı̧̧ma Selçuk Üniversitesi Bilimsel Araştırma Projeleri (BAP) Koordinatörlüğü tarafindan (BAP Proje No: 19401015) desteklenmiştir.

\section{Kaynakça}

Agawane, G.L., Shin, S.W., Moholkar, A.V., Gurav, K.V., Yun, J.H., Lee, J.Y. ve Kim, J.H. (2012), Non-Toxic Complexing Agent TriSodium Citrate's Effect on Chemical Bath Deposited ZnS Thin Films and Its Growth Mechanism, Journal of Alloys and Compounds, 535, 53-61.

Al-Ghamdi, A.A., Mahmoud, W.E., Yaghmour, S.J. ve Al-Marzouki, F.M. (2009), Structure and Optical Properties of Nanocrystalline $\mathrm{NiO}$ Thin Film Synthesized by Sol-Gel Spin-Coating Method, Journal of Alloys and Compounds, 486, 9-13.

Aly, S.A. ve Akl, A.A. (2015), Influence of Film Thickness on Optical Absorption and Energy Gap of Thermally Evaporated $\mathrm{Cds}_{0.1} \mathrm{Se}_{0.9}$ Thin Films, Chalcogenide Letters, 12, 489-496.

Bae, H.Y. ve Choi, G.M. (1999), Electrical and Reducing Gas Sensing Properties of $\mathrm{ZnO}$ and $\mathrm{ZnO}-\mathrm{CuO}$ Thin Films Fabricated by Spin Coating Method, Sensors and Actuators B: Chemical, 55, 47-54.

Baratto, C., Kumar, R., Faglia, G., Vojisavljević, K. ve Malič, B. (2015), P-Type Copper Aluminum Oxide Thin Films for GasSensing Applications, Sensors and Actuators B: Chemical, 209, 287-296.

Baturay, S., Tombak, A., Kaya, D., Ocak, Y.S., Tokus, M., Aydemir, M. ve Kilicoglu, T. (2016), Modification of Electrical and Optical Properties of CuO Thin Films by Ni Doping, Journal of Sol-Gel Science and Technology, 78(2), 422-429.

Cavusoglu, H. ve Aydin R. (2019), Complexing Agent Triethanolamine Mediated Synthesis of Nanocrystalline CuO Thin Films at Room Temperature via SILAR Technique, Superlattices and Microstructures, 128, 37-47.

Çavuşoğlu, H. (2019), Evaluating the Influence of Polyethylene Glycol as a Surfactant on CdO Films Grown by SILAR Method, Journal of Physics and Chemistry of Solids, 124, 67-72.

Çavuşoğlu, H. (2018), Structural, Morphological and Optical Studies of Nanostructured Cadmium Oxide Films: The Role of pH, Journal of Materials Science: Materials in Electronics, 29, 12777-12784.

Chandiramouli, R. ve Jeyaprakash, B.G. (2013), Review of CdO Thin Films, Solid State Sciences, 16, 102-110.

Das, M.R. ve Mitra, P. (2018), Influence of Nickel Incorporation on Structural, Optical and Electrical Characteristics of SILAR Synthesized CuO Thin Films, Journal of Sol-Gel Science and Technology, 87, 59-73.

Das, S. ve Alford, T.L. (2013), Structural and Optical Properties of Ag-Doped Copper Oxide Thin Films on Polyethylene Napthalate Substrate Prepared by Low Temperature Microwave Annealing, Journal of Applied Physics, 113, 244905.

Das, S. ve Jayaraman, V. (2014), $\mathrm{SnO}_{2}$ : A Comprehensive Review on Structures and Gas Sensors, Progress in Materials Science, 66, $112-255$.

Dey, A. (2018), Semiconductor Metal Oxide Gas Sensors: A Review, Materials Science and Engineering: B, 229, $206-217$.

Diachenko, O.V., Dobrozhan, O.A., Opanasyuk, A.S., Ivashchenko, M.M., Protasova, T.O., Kurbatov, D.I. ve Čerškus, A. (2018), The Influence of Optical and Recombination Losses on the Efficiency of Thin-Film Solar Cells with A Copper Oxide Absorber Layer, Superlattices and Microstructures, 122, 476-485.

Dodoo-Arhin, D., Leoni, M. ve Scardi, P. (2012), Microemulsion Synthesis of Copper Oxide Nanorod-Like Structures, Molecular Crystals and Liquid Crystals, 555, 17-31. 
Fadavieslam, M.R. (2018), Effect of Ag Doping on the Physical Properties of Tin-Sulfide Thin Films for Optoelectronic Applications Prepared by Spray Pyrolysis, Applied Physics A, 124, 596-602.

Gevorkyan, V.A., Reymers, A.E., Nersesyan, M.N. ve Arzakantsyan, M.A. (2012), Characterization of $\mathrm{Cu}_{2} \mathrm{O}$ Thin Films Prepared by Evaporation of CuO Powder, Journal of Physics: Conference Series, 350, 012027.

Huang, J., Wu, H., Cao, D. ve Wang, G. (2012), Influence of Ag Doped CuO Nanosheet Arrays on Electrochemical Behaviors for Supercapacitors, Electrochimica Acta, 75, 208-212.

Jackson, E.D., Mosby, J.M. ve Prieto, A.L. (2016), Evaluation of The Electrochemical Properties of Crystalline Copper Antimonide Thin Film Anodes for Lithium Ion Batteries Produced by Single Step Electrodeposition, Electrochimica Acta, 214, 253-264.

Kihal, R., Rahal, H., Affoune, A.M. ve Ghers, M. (2017), Electrodeposition of SnS Thin Film Solar Cells in the Presence of Sodium Citrate, Journal of Electrochemical Science and Technology, 8, 206-214.

Mukherjee, N., Show, B., Maji, S.K., Madhu, U., Bhar, S.K., Mitra, B.C., Khan, G.G. ve Mondal, A. (2011), CuO Nano-Whiskers: Electrodeposition, Raman Analysis, Photoluminescence Study and Photocatalytic Activity, Materials Letters, 65, 3248-3250.

Nair, M.T.S., Guerrero, L., Arenas, O.L. ve Nair, P.K. (1999), Chemically Deposited Copper Oxide Thin Films: Structural, Optical and Electrical Characteristics, Applied Surface Science, 150, 143-151.

Oh, S.W., Bang, H.J., Bae, Y.C. ve Sun, Y.-K. (2007), Effect of Calcination Temperature on Morphology, Crystallinity and Electrochemical Properties of Nano-Crystalline Metal Oxides $\left(\mathrm{Co}_{3} \mathrm{O}_{4}, \mathrm{CuO}\right.$, And $\left.\mathrm{NiO}\right)$ Prepared via Ultrasonic Spray Pyrolysis, Journal of Power Sources, 173, 502-509.

Papurello, R.L., Cabello, A.P., Ulla, M.A., Neyertz, C.A. ve Zamaro, J.M. (2017), Microreactor with Copper Oxide Nanostructured Films for Catalytic Gas Phase Oxidations, Surface and Coatings Technology, 328, 231-239.

Qin, H., Zhang, Z., Liu, X., Zhang, Y. ve Hu, J. (2010), Room-Temperature Ferromagnetism in CuO Sol-Gel Powders and Films, Journal of Magnetism and Magnetic Materials, 322, 1994-1998.

Qiu, G., Dharmarathna, S., Zhang, Y., Opembe, N., Huang, H. ve Suib, S.L. (2012), Facile Microwave-Assisted Hydrothermal Synthesis of CuO Nanomaterials and Their Catalytic and Electrochemical Properties, The Journal of Physical Chemistry C,116, $468-477$.

Rafea, M.A. ve Roushdy, N. (2009), Determination of the Optical Band Gap for Amorphous and Nanocrystalline Copper Oxide Thin Films Prepared by SILAR Technique, Journal of Physics D: Applied Physics, 42, 015413.

Raghavendra, P.V., Bhat, J.S. ve Deshpande, N.G. (2018), Visible Light Sensitive Cupric Oxide Metal-Semiconductor-Metal Photodetectors, Superlattices and Microstructures, 113, 754-760.

Ramírez-Ceja, D., González, L.A., Escorcia-García, J. ve Martínez-Enríquez, A.I. (2016), Characterization of PbS Thin Films Obtained by Chemical Bath at Low Temperature Using Sodium Citrate as Complexing Agent, MRS Advances, 1, 2623-2628.

Ramírez-Ortiz, J., Ogura, T., Medina-Valtierra, J., Acosta-Ortiz, S.E., Bosch, P. de los Reyes, J.A. ve Lara, V.H. (2001), A Catalytic Application of $\mathrm{Cu}_{2} \mathrm{O}$ and $\mathrm{CuO}$ Films Deposited Over Fiberglass, Applied Surface Science, 174(3-4), 177-184.

Sanguanruang, S., Leotphayakkarat, R., Fangern, N., Koonsaeng, N. ve Chawengkijwanich, C. (2011), Preparation and Characterization of Thin Films $\mathrm{TiO}_{2}$ Prepared by Various Amount of Triton X-100 Surfactant for Photodegradation of a Dye Pollutant, Advanced Materials Research, 233-235, 2863-2870.

Shrividhya, T., Ravi, G., Hayakawa, Y. ve Mahalingam, T. (2014), Determination of Structural and Optical Parameters of CuO Thin Films Prepared by Double Dip Technique, Journal of Materials Science: Materials in Electronics, 25(9), 3885-3894.

Singh, I., Kaur, G. ve Bedi, R.K. (2011), CTAB Assisted Growth and Characterization of Nanocrystalline CuO Films by Ultrasonic Spray Pyrolysis Technique, Applied Surface Science, 257, 9546-9554.

Terasako, T., Murakami, T., Hyodou, A. ve Shirakata, S. (2015), Structural and Electrical Properties of CuO Films and n-ZnO/p-CuO Heterojunctions Prepared by Chemical Bath Deposition Based Technique, Solar Energy Materials and Solar Cells, 132, 74-79.

Ukoba, K.O., Eloka-Eboka, A.C. ve Inambao, F.L. (2018), Review of Nanostructured NiO Thin Film Deposition Using the Spray Pyrolysis Technique, Renewable and Sustainable Energy Reviews, 82, 2900-2915.

Vila, M., Díaz-Guerra, C. ve Piqueras, J. (2010), Optical and Magnetic Properties of CuO Nanowires Grown by Thermal Oxidation, Journal of Physics D: Applied Physics, 43(13), 135403.

Xia, H., Lai, M.O. ve Lu, L. (2011), Nanostructured Manganese Oxide Thin Films as Electrode Material for Supercapacitors, Journal of The Minerals, Metals \& Materials Society, 63(1), 54-59.

Yang, C., Su, X., Xiao, F., Jian, J. ve Wang, J. (2011), Gas Sensing Properties of CuO Nanorods Synthesized by A MicrowaveAssisted Hydrothermal Method, Sensors and Actuators B: Chemical, 158, 299-303.

Znaidi, L. (2010), Sol-Gel-Deposited ZnO Thin Films: A Review, Materials Science and Engineering: B, 174(1-3), 18-30. 